\title{
DOS PROGRAMAS OFICIAIS PARA A EDUCAÇÃO RURAL AOS PROJETOS DE EDUCAÇÃO DO CAMPO DOS MOVIMENTOS SOCIAIS
}

\author{
OF THE OFFICIAL PROGRAMS FOR THE RURAL EDUCATION TO THE \\ PROJECTS OF EDUCATION OF THE FIELD OF THE SOCIAL MOVEMENTS
}

Mara Rita Duarte de Oliveira ${ }^{1}$

\begin{abstract}
Resumo
O presente trabalho tem como objetivo central discutir os programas oficiais destinados à educação das populações do campo, fazendo uma incursão dos anos 1930 até os anos de 1990. Apontando nesse percurso o surgimento das experiências de propostas educativas dos Movimentos sociais ligados à luta pela terra, em especial, dos Movimentos dos Trabalhadores Rurais (MST) e da Federação dos Trabalhadores da Agricultura (FRETAGRI), tais propostas desenvolvidas no Estado do Pará, são experiências de resistência às propostas oficiais homogenizadoras que deslegitimam e aviltam a identidade camponesa. Ainda, no campo das experiências educativas dos movimentos sociais aponta o caráter emancipador de tais propostas e a contribuição dessas para novos itinerários educativo da educação campo.
\end{abstract}

Palavras chaves: Educação, Campo, Movimentos sociais, Emancipação

\begin{abstract}
This paper aims to discuss the central official programmes for education of the populations of the field, making an incursion of the years 1930 to the year 1990 . Point in that journey the emergence of the experiences of educational proposals of social movements linked to the struggle for land, in particular, the Movement of Rural Workers (MST) and the Federation of Workers in Agriculture (FRETAGRI), such proposals developed in the state of Idaho, are experiences of resistance to proposals that homogenizadoras official deslegitimam and humiliate the identity peasant. Still, in the field of educational experiences of social movements shows the character of emancipating such proposals and the contribution of these new routes to educational education field.
\end{abstract}

Key words: Education, Countryside, Social Movements, emancipation 


\section{A trajetória da educação rural nos programas oficiais (1930 a 1990)}

Ao iniciarmos o debate em torno da educação rural à educação do campo $^{2}$, tivemos como preocupação colocar no centro das discussões o "tratamento dispensado" pelos dirigentes políticos à educação rural ao longo da história da educação brasileira, considerando as transformações sociais, políticas e econômicas e as conquistas que foram ocorrendo dentro desta área até chegarmos à construção do projeto popular de educação para as escolas do campo.

Para nós cabe realizarmos uma incursão dentro destes paradigmas educacionais, indo ao encontro do momento em que a educação rural tornou-se mais especificamente alvo de inúmeros programas oficiais do governo para o desenvolvimento social e econômico da sociedade, sendo esta educação entendida como um caminho para a redenção do(a) homem/mulher do campo e de uma forma mais ativa de inclusão do Brasil na modernidade do século XX.

Foi a crescente industrialização e a urbanização no mundo ocidental que veio a implicar mais profundamente na transformação do gênero da vida urbana (QUEIROZ, 1978, p. 56) causando também inúmeras modificações na vida rural. Poderíamos afirmar que no período que se inicia a industrialização no Brasil apenas algumas cidades conseguiram apresentar uma certa diferença de classes sociais, a homogeneidade no meio rural em algumas regiões se apresenta com a mesma estrutura anterior e em outras houve poucas alterações, o que quer dizer que em regiões mais pobres as diferenças entre o meio rural e o urbano em relação ao modo de viver (QUEIROZ, 1978, p. 59) eram quase imperceptíveis.

Durante muitos anos a educação destinada às classes populares do campo, vinculou-se a um modelo importado da educação urbana e ao mesmo tempo esteve a serviço do interesse das oligarquias rurais e das oligarquias 
agrário-industriais. Tal tratamento tem um fundo de descaso e subordinação em que esteve, em alguns casos ainda está, o meio rural.

Desta forma muitos programas educacionais foram elaborados com intuito de acompanhar as inovações no campo político-econômico e social da sociedade brasileira no século XX. Tais inovações exigiram que o estado ${ }^{3}$ se tornasse cada vez mais responsável pela oferta da educação, uma vez que agora não só a grande aristocracia cafeicultora e a oligarquia agrária procuravam a educação, a instrução, mas também uma outra parte da população, principalmente a pequena burguesia (comerciantes e profissionais liberais), despossuídas da riqueza da terra, mas concentradora de poder econômico e de relativo prestígio social, que reivindicava para si a escolarização como forma de garantir-se na disputa pelo poder.

Foi a partir da Primeira República que as elites mais tradicionais tiveram de, ainda que limitadamente, "abrir mão" do controle da oferta da escolarização em favor das classes emergentes e populares. Entretanto, dentro da política educacional prescrita pela dita "República educadora" ainda não havia programas educacionais de caráter específico destinado à escolarização no meio rural.

No período que sucedeu a República Velha, mais ou menos a partir da década de 1920, surgiram movimentos que objetivaram romper com a antiga ordem oligárquica e implantar definitivamente o modelo capitalista de produção para a modernização do Brasil. Tais movimentos, que exigiam mudanças no modelo produtivo para impulsionar a transferência de uma base econômica da área agrícola para a área industrial, impuseram à educação escolar a necessidade de adequar-se ao novo contexto, tendo de se adaptar aos novos papéis que the eram exigidos, quais sejam: qualificar mão de obra para atender à economia industrial emergente e fortalecer o capitalismo nacional.

Ainda na década de 20, com o crescimento do grande fluxo migratório interno, com as populações do interior brasileiro saindo do campo em busca de trabalho em áreas mais industrializadas, ocorreu, conseqüentemente o inchaço 
populacional nas cidades o que originou graves problemas de ordem social e política. Nesta ocasião, começa a aparecer algum interesse em torno da educação rural, no sentido de conter a migração rural e urbana e de tal modo a evitar um colapso nas cidades. Desta forma surge o que foi denominado de ruralismo pedagógico, que consistia em uma ação voltada para "prender" o homem/mulher ao campo, evitando-se ainda o inchamento populacional das grandes cidades que iniciavam seu processo de urbanização e industrialização. Segundo Leite esse movimento pode ser definido da seguinte maneira:

O ruralismo no ensino permaneceu até a década de 1930, uma vez que a escolaridade mantinha-se vinculada à tradição colonial e distanciada das exigências econômicas do momento. Somente após os primeiros sintomas de uma transformação mais profunda no modelo econômico agroexportador é que a escolaridade tomaria posições mais arrojadas. (LEITE, 1999, p. 29).

Com as transformações que vão se construindo ao longo da década de 20, em especial no campo, no que se refere aos aspectos político-ideológicos surgiram expressivas mudanças, apareceram movimentos culturais e pedagógicos e começou-se a respirar outros ares no Brasil.

Com a chegada da "revolução" de 1930 houve a conquista da hegemonia política pelo grupo industrial-urbano que manteve a prática das negociações com variados setores inclusive o agrário. Nesse momento, são organizadas na educação duas frentes: uma para continuar a conter a migração no campo e outra técnico-profissional para atender as demandas das cidades.

É também nesse período que o governo cria o Ministério da Educação e Saúde com a finalidade de valer-se da educação como instrumento para sanear as epidemias que se difundiam no meio rural, e também há incentivo às reformas de política pública, com a tendência de fazer a volta aos campos como forma de deter a atração das classes rurais para a cidade e com essa preocupação de povoar e sanear a zona rural (PAIVA, 1987, p.127). 
Também se intensificaram as reivindicações pela ampliação da oferta do ensino sob responsabilidade da União, reclamava-se cada vez mais a intervenção do poder estatal a favor do ensino público. Assim, em 1931 realizouse a IV Conferência Nacional de Educação que teve como tema "as grandes diretrizes da educação popular no Brasil, com a preocupação central a intervenção federal na difusão do ensino primário, técnico, normal e profissional" (XAVIER, 2002, p.17).

Tais debates de cunho ideológico e pedagógico são influenciados pela iniciativa de alguns educadores, que em 1932 lançam o Manifesto dos Pioneiros da Educação que impulsionou grandes transformações na educação brasileira. Para esses entusiastas da educação, para que houvesse desenvolvimento no Brasil era preciso desenvolver as forças econômicas e sociais, sendo necessárias reformas tanto no âmbito econômico quanto educacional.

Destarte, as ações educacionais reservadas ao meio rural, também foram influenciadas pelo movimento de renovação educacional. Assim, a partir de 1933 que se inicia a Campanha de alfabetização na Zona Rural, em um clima ainda de ruralismo pedagógico, organizaram-se cursos de capacitação para os professores. Em 1935 foi realizado o 1ํㅡㄹ Congresso Nacional do Ensino Regional, que contribui para a fundação da Sociedade Brasileira da Educação Rural, em 1937, que tinha como objetivo propagar a educação rural (PAIVA, 1987, p.129). Proliferaram-se os planos de educação, nos quais recomendava-se escolas ambulantes nas regiões de menor densidade geográfica.

É exatamente com o começo do Estado Novo (1937 a 1945), que se fortaleceu a preocupação com a escolarização da população do meio rural, frente à questão dos permanentes índices de analfabetismo e do fluxo migratório interno que continuava a ser um incômodo às elites urbanas. Eis como surgem os primeiros programas de oferta de educação no meio rural, no sentido de manutenção produtiva e desenvolvimento da sociedade política e civil.

Devido às mudanças sócio-econômicas que aconteceram no país, 
ocorreu o reconhecimento da importância da escola para a sociedade: a escola passa a ser entendida como espaço generalizado de socialização e transmissão de conhecimento (NASCIMENTO, 2001, p.99), importante para a ascensão social dos indivíduos. Por isso Vargas fecha as escolas alemãs e japonesas, assim como as escolas livres de orientação anarquista, e obriga aos imigrantes a freqüentarem as escolas brasileiras (NASCIMENTO, 2001, p. 101), como forma de difundir e inculcar os valores nacionalistas do Estado Novo.

As proposições getulistas do Estado Novo de certa forma mantiveram a tradição escolar brasileira, garantindo a obrigatoriedade e a gratuidade da escolaridade, porém dando ênfase nas escolas primárias e secundárias ao desenvolvimento de uma política educacional voltada para o ensino vocacional urbano destinado especialmente as classes populares. (LEITE, 1999, p. 30).

$\mathrm{Na}$ Era Vargas o governo mostra cada vez mais interesse nas possibilidades ideológicas da ação educativa, assim a educação era entendida como um instrumento do estado e, como tal, deveria servir aos seus interesses.

Surge a Campanha Nacional de Educação Rural (CNER 1952 a 1963), na qual se reflete a orientação dos organismos internacionais em relação à educação dos adultos analfabetos, instalando suas missões em pequenas comunidades do interior do país (PAIVA, 1987, p.161). O objetivo da CNER era contribuir para acelerar o processo evolutivo do homem rural, despertando nele o espírito comunitário, a idéia, o valor humano e o sentido de suficiência e responsabilidade para que não se acentuassem as diferenças entre a cidade e o campo (PAIVA, 1987,p.197). As atividades da CNER tiveram dois pontos de apoio: as missões e os centros rurais de treinamento destinados a professores leigos e à preparação dos filhos dos agricultores para atividade agrícola (PAIVA, 1987, p. 201).

Além desses programas, podemos citar outros importantes como: a) A Comissão Brasileiro-Americana de Educação das Populações Rurais (CBAR) que 
tinha por objetivo investigar e pesquisar as condições econômicas, sociais e culturais da vida rural brasileira; contribuir para o aperfeiçoamento dos padrões educativos, sanitários, assistenciais, cívicos e morais das populações do campo; preparar técnicas para atender às necessidades da educação de base, etc. b) Centro de Treinamento; c) Semanas Ruralistas; d) Clubes Agrícolas; e) Serviço Social Rural (SSR), o qual mantinha um sistema de conselhos regionais, sediados nas capitais dos Estados em todo território brasileiro. Havia também a Associação de Crédito e Assistência Rural (ACAR), hoje EMATER, que também se investiu no Programa de Extensão Rural que objetivava o combate à carência, à subnutrição e às doenças (LEITE, 1999, p.33).

$\mathrm{Na}$ implantação destes programas não foram levadas em consideração as especificidades de cada região, ou seja, não houve estudos ou pesquisas que apontassem as reais necessidades e os problemas enfrentados por cada região a ser beneficiada. Esses programas são despejados em uma determinada região, simultânea ou sucessivamente, sem que seus efeitos sejam cientificamente avaliados. (CALAZANS et al, 1981, p. 167).

Assim, a educação rural é chamada para se ajustar às políticas educacionais estabelecidas pelo projeto do estado, entretanto ainda havia uma grande diferença na forma como as populações do campo e da cidade eram tratadas. Enquanto o setor urbano era tido como moderno e desenvolvido, o setor rural ainda era considerado como tradicional e atrasado, dentre outros adjetivos de caráter pejorativo dirigido ao campo e suas populações. A educação rural em primeiro lugar, apesar de numerosos programas desenvolvidos, sempre representou uma fatia muito pequena e marginal nas preocupações do setor público (CALAZANS, 1981, p.162).

Diante da pouca operacionalidade dos programas realizados até então e do agravamento das disparidades socioeconômicas entre as regiões brasileiras, vão se desenvolver, durante as décadas de 1960 e 1970, outros programas de atendimento à carência rural. Entretanto, todos ainda continuavam na mesma 
lógica dos anteriores e, por isso, seus resultados não foram menos desastrosos. Entre as novas instituições, não podemos deixar de citar os de cunho setorial, tais como SUDENE, SUDESUL, INCRA E SUDAM ${ }^{4}$, todos com o objetivo de fixar o homem/ mulher no campo e ao mesmo tempo conter a expansão dos movimentos agrários e das lutas camponesas (LEITE, 1999:41) que se alastravam pelo Brasil, contaminando os movimentos populares e estimulando as organizações sindicais como: Movimento de Educação de Base (MEB) e os Centros de Cultura Popular (CCP), ambos influenciados pela proposta de educação do Sistema Paulo Freire (GOHN, 1994, p.44).

Os resultados dos programas governamentais foram os fortalecimentos da hegemonia social da classe dominante, da discriminação sócio-cultural e do aumento das dependências econômicas e sociais dos segmentos subalternizados, em especial das populações rurais que estão em regiões menos desenvolvidas do país. Deste modo identificamos que esta é a linha dominante e, que pode ser percebida nos projetos educacionais realizados nos dias atuais sob responsabilidade das instituições como Ministério da Educação e Cultura, INCRA e EMATER entre outros. (...) que se referem às perspectivas do governo para educação rural na década de oitenta. (CALAZANS, 1981, p. 181).

Dentro desse modelo educacional brasileiro hegemônico, a educação escolar constitui-se em um forte espaço de reprodução e produção das classes sociais e de seus conjuntos de ideologias, como ocorridas nas décadas anteriores, no qual as políticas educacionais implementadas materializam os projetos definidos e articulados pelo estado que estão afinadas com o modelo de "governabilidade", implicando na construção do conhecimento social muitas vezes voltado unicamente para a produtividade econômica.

E apesar desses diversos mecanismos de reprodução social apresentados por essas políticas implementadas no meio educacional rural, numa tentativa de homogeneizar a educação, desvalorizando as diferenças históricas e 
culturais construídas dentro dos processos educativos e que se desencadeiam no interior das relações sociais, não podemos deixar de lembrar o alerta de Arroyo ao afirmar que há uma outra pedagogia em marcha (1995, p.80) e que a história das lutas entre as classes sociais não se limitam à luta pelo poder, mas se constituem impulsionadoras da história da humanidade que não aguardam passivamente seu destino, mas ao contrário: articulam-se em torno de suas lutas para garantir seus direitos, sua dignidade e sua participação democrática na sociedade.

Deste modo, as classes hegemônicas, através dessas políticas educacionais, se revestem de uma outra roupagem na tentativa de continuar no controle da oferta da escolarização. Porém, os movimentos sociais, opositores a essas classes, conscientes de seu poder de articulação, empunham bandeiras de lutas por uma educação alternativa que se materialize em uma pedagogia da resistência.

Frente a essa realidade, o desafio posto, tem sido pensar em uma educação do campo, em uma escola do campo, que visualize as mudanças sociais e consiga acompanhá-las, ao mesmo tempo em que possibilite a formação omnilateral ${ }^{5}$, vinculando o saber universal às experiências de vida dos(as) educandos(as), para que se tornem sujeitos participativos, dialógicos, humanizados e capazes de estabelecer os alicerces de uma nova ordem social.

Deste modo, mais recentemente as transformações sociais e a revitalização dos movimentos ligados à luta do campo, influenciaram significativamente na definição de novas diretrizes para a educação básica do campo, essas se referem desde a oferta da escolarização a seu financiamento. Encontramos na década de 90 um novo formato de educação destinada ao meio rural6. O governo federal, através de parceria com os vários ministérios e com movimentos ligados à luta do campo, lançou vários programas e projetos para a educação do campo. Esses são conquistas históricas desses movimentos que sempre estiveram a frente de seu tempo na luta pela democratização do ensino no Brasil. Entretanto, é preciso estar alerta para que tais conquistas não sejam 
transformadas em instrumento de cooptação e controle do estado sobre a ação da sociedade civil organizada.

Como fruto dessas lutas contemporâneas no campo educacional, foi promovido em 1998, em Luziânia/GO, a Conferência Nacional por uma Educação Básica no Campo, sob a coordenação da CNBB, MST, UNESCO e UNICEF, momento em que se pretendeu analisar experiências educacionais e de formação profissional desenvolvidas em áreas rurais ligadas ao propósito de construir este novo projeto nacional de educação.

Assim sendo, na conferência foram definidas diretrizes para a construção da educação básica do campo, em que:

\begin{abstract}
A educação do campo precisa ser uma educação específica e diferenciada, Isto é, alternativa. Mas, sobre tudo, deve ser uma educação, no sentido amplo de processo de formação humana, que constrói referências culturais e políticas para a intervenção das pessoas e dos sujeitos sociais na realidade, visando a uma humanidade mais plena e feliz". (Relatório da Conferência Nacional: Por uma Educação Básica do Campo 1998, p.24).
\end{abstract}

Nascem, então, as diretrizes para a construção do projeto popular para as escolas do campo, ao mesmo tempo em que se fortalecem as iniciativas já existentes da Pedagogia da Alternância ${ }^{7}$, todas vinculadas a um projeto maior de sociedade e ao mesmo tempo fundamentadas na legislação da educação brasileira, que como conquista dessa luta histórica dos movimentos sociais conseguiram garantir o reconhecimento da singularidade, da importância e contribuição da educação do campo para o desenvolvimento social.

\title{
2 OS PROJETOS DA EDUCAÇÃO DO CAMPO DESENVOLVIDAS NO PARÁ
}

\subsection{O MST e a Pedagogia da Terra.}


A história da proposta pedagógica do MST pode ser encontrada nos assentamentos e acampamentos espalhados pelo Brasil, desenvolvendo-se desde a ciranda infantil ao ensino superior. Toda essa história teve várias fases: a de 1979 a 1984 é a fase do desenvolvimento do Movimento dos Trabalhadores Sem Terra, quando o movimento começa a se organizar principalmente nos Estados de Rio Grande do Sul, Santa Catarina, Paraná, São Paulo e Mato Grosso do Sul, e a fase de sua formação efetiva, no ano de 1984.

No período de 1985, realizou-se o $1^{\text {a }}$ Congresso Nacional do MST. A partir de então, começa a ser articulado o Setor de Educação, que teria a responsabilidade de junto aos(às) assentados(as) e acampados(as) e ainda educadores e educadoras gestar a proposta de educação do movimento, que não se desvinculasse sobretudo do respeito à diversidade sócio-cultural de cada região.

A preocupação central do Setor de Educação, desde sua criação, era a formação de educadores(as). Isso foi aumentando gradativamente, quando nas escolas iam surgindo "profissionais" que se colocavam radicalmente contra a proposta defendida pelo Movimento. A atitude daqueles "profissionais" representou para o MST um duro golpe: era necessário repensar a formação docente, pois, o ambiente escolar não poderia ser aquele que, convencionalmente, vinha sendo proposto para as populações rurais.

Começa a luta por uma escola do campo nos acampamentos e assentamentos do MST. Compreendia-se que o acampamento e o assentamento do sem-terra do MST deveria ter uma escola e, de preferência, não uma escola qualquer (CALDART, 2001:45), mas uma escola inclusiva, que fosse assumida pelos sujeitos que a conquistaram, que ao mesmo tempo fortalecesse a luta dos povos do campo para serem reconhecidos como sujeitos sociais. E assim, ajudasse no processo de humanização do conjunto da sociedade, com suas lutas, sua história, seu trabalho, seus saberes, sua cultura, seu jeito (CALDART, 2001:66). 
O ambiente educativo das escolas do MST propõe a organização e reorganização das relações sociais entre educadores(as) e educandos, combina no mesmo movimento pedagógico as diversas práticas sociais e educativas, cultiva a vida como um todo: a luta, o trabalho, a organização coletiva, o estudo, as atividades culturais, o cultivo da terra, da memória (CALDART, 2001, p.80).

A formação das educadoras e educadores é o centro dessa proposta, pois não há escolas no campo sem a formação dos sujeitos sociais do próprio campo, que assumam e lutem por esta identidade e por um projeto de futuro (CALDART, 2001, p.66). Toda a formação está marcada pela reflexão constante da prática e assim transforma-se em práxis educativa que alimenta e realimenta a vontade dos educadores e educadoras de fazerem uma escola diferente, que não seja excludente e seletiva, que não transforme aqueles que por ela passam em sujeitos sombrios e amargurados.

Atualmente, o MST também desenvolve em parceria com a Universidade Federal do Pará ${ }^{8}$, o Programa Nacional de Educação na Reforma Agrária (PRONERA $)^{9}$, que se estende desde alfabetização de jovens e adultos à formação acadêmica de nível superior dos educadores e educadoras do MST, além das escolas de ensino fundamental difundidas nos acampamentos e assentamentos.

Toda a proposta do MST é uma outra pedagogia em marcha, que se contrapõe ao modelo oficial, que denuncia o abandono da gente do campo e exige a reforma agrária como um caminho para restituir a esses(as) cidadãos(as) a dignidade de terem seus direitos reconhecidos. Para o MST a educação e a luta social não se desvinculam, uma fortalece a outra e caminham juntas para a formação da nova sociedade brasileira. 


\title{
2.2 A ESCOLA FAMÍLIA AGRÍCOLA (EFA)
}

O Projeto de Educação para os jovens agricultores da região de Marabá-PA surgiu em outubro de 1993, no I Encontro de Jovens Camponeses dos STRs da FATA/CAT e foi inspirado principalmente nas experiências desenvolvidas nos estados do Maranhão e Espírito Santo, como também de outras experiências desenvolvidas na França. Para a efetivação da proposta, foi criada uma Comissão de Articulação para implantação da Escola Família Agrícola (EFA), formada por sindicalistas e jovens agricultores. Inicialmente, fundou-se a Associação de Pais e posteriormente a EFA. Deste modo:

\begin{abstract}
A EFA iniciou seu funcionamento no dia 18 de março de 1996, com uma primeira turma de 22 alunos, que iniciaram a partir da $5^{\underline{a}}$ série até $8^{\mathrm{a}}$ série do ensino fundamental, esta turma concluiu o curso em dezembro de 1999 com 13 alunos. Em abril de 1998 deu início a formação de uma nova turma com 22 alunos, atualmente 15 alunos estão em formação. Negociação com os órgãos públicos parceiros iniciará a partir de agosto de 2000 a formação de uma nova turma com 25 alunos, provenientes dos 17 municípios de abrangência da FETAGRI-Regional Sudeste. (Projeto pedagógico da escola família Agrícola - EFA, 2000, p. 07).
\end{abstract}

A EFA é a associação de famílias, profissionais e entidades, que juntas buscam a promoção do desenvolvimento do meio rural através da educação, utilizando a Pedagogia da Alternância. O objetivo principal da EFA é promover o desenvolvimento sustentável do meio rural, estimulando o espírito de solidariedade através da formação do(a) jovem agricultor(a) que, possuidor de um saber técnico aliado a um saber universal, possa contribuir para esse desenvolvimento, fortalecendo a identidade do agricultor familiar e revitalizando as práticas culturais desses sujeitos na sua realidade local.

As experiências da Pedagogia da Alternância para a formação de jovens agricultores é praticada no Brasil de forma diversificada, através das EFA's Escolas Famílias Agrícolas, CFR's - Casas Familiares Rurais, ECR's-Escolas Comunitárias Rurais e outras denominações ${ }^{10}$. 


\subsection{CASAS FAMILIARES RURAIS (CFR'S)}

No Brasil, as propostas em torno da implantação das Casas Familiares Rurais datam de 1984 , onde se localizam as primeiras iniciativas no sentido de consolidar-se um programa de educação para os jovens ${ }^{11}$ do meio rural, que ao mesmo tempo em que possibilitassem uma formação geral e que pudesse complementar essa, com a formação prático-teórica que viesse colaborar para a intervenção desses jovens em suas realidades locais.

A CFR é uma instituição educativa de ensino informal, que visa oferecer aos jovens do meio rural uma formação integral adequada a sua realidade, que thes permitam atuarem no futuro como profissionais no meio rural. O projeto é regido por uma Associação de Agricultores, do município, através de um Conselho de Administração eleito em Assembléia Geral, que tem o objetivo de participar do processo educativo dos jovens e administrar o projeto. (Programa de educação rural para o estado do Pará: casas familiares Rurais do Norte e Nordeste, Arcarfar, 1999, p. 03).

A primeira experiência registrada foi no estado de Pernambuco, na cidade de Riacho das Almas e no município de Barracão, Estado do Paraná, no ano de 1989. Atualmente, existem 39 CFR's no Estado do Paraná, 16 em Santa Catarina e 7 no Rio Grande do Sul.

Quanto ao Estado do Pará podemos afirmar que:

A proposta de instalação de uma Casa Familiar Rural nasceu do anseio dos agricultores, lideranças e profissionais da educação, preocupados com a busca de uma alternativa de ensino-formação para os jovens residentes no meio rural. As discussões sobre um Projeto Piloto da CFR aconteceram na Transamazônica, a partir de junho de 1994, através de um encontro, em Altamira, promovido pelo Movimento pela Sobrevivência na Transamazônica (MPST), em parceria com 0 Laboratório Agroecológico da Transamazônica (LAET), que contou com a presença do assessor das Casas Familiares Rurais no Brasil" (Programa de educação rural para o estado do Pará: casas familiares Rurais do Norte e Nordeste, Arcarfar, 1999, p. 03). 
Todas as experiências citadas são fundamentais para se compreender os processos educativos que se desencadeiam no Estado do Pará, já que além das escolas ditas formais em que o tempo-comunidade e o tempo-escola estão desassociados assim como a relação escola/ trabalho estão colocadas como elementos dicotômicos no processo de aprendizagem de alunos e alunas, diferente desta educação escolar oficial, normativa, marcada por um modelo burocrático de escola. Essas experiências são frutos da organização popular, dos movimentos sociais e entidades não-governamentais e governamentais que caminham na direção da construção de uma educação popular.

\section{CONSIDERAÇÕES FINAIS: CONTRIBUIÇÕES DE UMA EDUCAÇÃO EMANCIPADORA PARA A EDUCAÇÃO DO CAMPO}

A prática constante da reflexão de nossa experiência de pesquisa na zona rural de Rondon do Pará e as nossas vivências na região Sul e Sudeste do estado do Pará, mostraram - nos que os programas e projetos educacionais destinados ao campo têm se caracterizado, ainda, por um distanciamento entre o proclamado e o efetivado, porque nesse processo não são consideradas as manifestações sócio-culturais da infância e da juventude e as formas, níveis e estágios diferenciados de aprendizagem dos(as) alunos(as) que conseguem ingressar no universo escolar.

A educação escolar, como já dissemos em outras ocasiões, tem sido implantada, historicamente, através de um paradigma da reprodução social, contribuindo para que seus envolvidos (educadores e educadoras, educandos e educandas) transfigurem-se em pessoas insensíveis, passivas e subservientes. Essa educação escolar se sustenta na hierarquia, na normatização e reprodução das relações sociais de produção caracterizada pela submissão das classes despossuídas à classe burguesa dominante.

A escola que se nos oferecem de um modo geral, é uma instituição conservadora e resistente à idéia de movimento e obsta qualquer tipo de vínculo 
direto com as lutas socais (CALDART, 2001, p. 76). É preciso muita resistência para adequar-se ou sobreviver ao seu molde. Poderíamos, então até comparar o processo (des)educativo destinado às classes populares com a barbárie, pois destrói o prazer de aprender e de buscar o conhecimento. Assim, o ato educativo legitima, dessa maneira, as formas de opressão social.

Nesse modelo educativo, a escola constitui-se em representação da ideologia dominante, posto que o currículo escolar materializa essa ideologia de maneira explícita e implícita nas práticas educativas que se desenvolvem no meio escolar.

A educação escolar por nós analisada ao longo deste trabalho, aquela mesma que se processa e fundamenta-se muito mais em uma lógica na qual a escola é vista apenas como um espaço de redução do elemento educativo à institucionalização de um saber que é necessário ser assimilado de geração em geração (ARROYO, 1991, p.81), do que em uma lógica contrária, na qual a escola deve ser vista como um espaço social de conflito e de construção de novas perspectivas, rompendo-se, assim, com o imposto e o normativo e construindo outros caminhos para a educação.

A própria diversidade sócio-cultural dos(as) alunos(as) é reduzida às diferenças apenas dentro do campo cognitivo, desconsiderando-se as diferenças sócio-culturais e a totalidade das dimensões humanas dos educandos enquanto sujeitos sócio-culturais portadores de uma identidade singular que os revela, à medida que interagem com o meio social. Dentro desse processo educativo, esvazia-se a criatividade e a potencialidade dos atores escolares no sentido de construírem suas dinâmicas particulares e de se desenvolverem de forma plena ou omnilateralmente.

O que temos visto no Brasil é que as camadas populares foram alijadas do processo decisório sobre seus próprios destinos e isso ainda está distante de ser mudado. Todavia, encontramos resistências de alguns segmentos sociais que atuam no campo e que reclamam uma maior 
participação no direcionamento do país para a superação de suas dificuldades sociais, estabelecendo vínculos entre si e se organizando em torno do bem comum.

Para alterar essa realidade é preciso a defesa e a construção de um projeto de educação de qualidade, que resgate a dignidade social das camadas populares, tão marginalizadas e desprovidas de suas condições básicas de sobrevivência. Em outras palavras, acenamos para uma proposta de educação básica que assuma, de fato, a identidade do campo, não só como ajuda efetiva no contexto específico de um novo projeto de desenvolvimento no campo (Conferência Nacional por uma educação básica no Campo, 1998, p. 29).

A educação, especialmente aquela que deve se processar na realidade do campo deve ser entendida como meio de apropriação e possibilidade de criação de conhecimentos para os indivíduos através do domínio da leitura e da escrita inclusive, gerando um cidadão capaz de inserir-se criticamente no universo social da própria leitura e da escrita, agindo numa perspectiva transformadora.

Assim, para motivar nossas proposições no universo do possível, já elucidamos vários projetos em curso e outros já realizados em décadas anteriores, entre os quais a Escolas Família Agrícola (EFAs), as escolas dos assentamentos e acampamentos do Movimento dos Trabalhadores Sem Terra (MST), Casas Familiares Rurais (CFR's) e o Programa Nacional de Educação na Reforma Agrária (PRONERA).

Essas experiências são marcadas pela compreensão de que é urgentemente preciso uma escola voltada para a realidade daqueles que habitam o campo, em igualdade social de oferta de escolarização e de qualidade de ensino. E é assim que se vão construindo tais iniciativas no contínuo devir dos processos históricos e sociais, sem se desconsiderar, é claro, a realidade desses grupos. 
E é com base na crença de dar continuidade à transformação social e à cultura popular, que os movimentos sociais insistem em fazer, em construir, a história e celebrar seus compromissos com as lutas das populações do campo.

Acreditamos que não basta à otimização do acesso à escolarização básica, mas é necessário afiançar (e acima de tudo) os investimentos em projetos educacionais que se articulem melhor com as comunidades as quais devam beneficiar e não as marginalizando, em nenhum momento, dos processos decisórios.

Eis aí o porquê da importância das experiências exemplificadas anteriormente, porquanto constituem contribuições fundamentais para uma escola do campo, emancipatória, reivindicativa e singular. Uma escola que seja um espaço político e pedagógico ao mesmo tempo, em que o tempo-escola e o tempo-comunidade se equacionem, onde professores e professoras assumam uma identidade cultural que thes pertence e que os(as) educadores(as) desenvolvam práticas alternativas de ensino que desmonte a linguagem da lógica da dominação (GIROUX E MACLAREN, 1995, p.140).

Uma ação docente-discente que abarque a dimensão cotidiana da escola, em que os sujeitos escolares atribuam sentido às suas vidas através das complexas formas históricas, culturais e políticas e não apenas as incorporem, mas que sejam capazes de produzi-las (GIROUX E MACLAREN, 199, p.145).

A escola deve ser um lugar gostoso (ASSMANN, 2000, p. 23) e ao mesmo tempo um espaço criativo para que os sujeitos escolares possam construir novos conhecimentos. O conhecimento só emerge em sua dimensão vitalizadora quando tem algum tipo de ligação com o prazer. (ASSMANN, 2000, p.30). Somente quando prazer e conhecimento estabelecem ligações, é que a aprendizagem flui, e não como um amontoado de coisas que vão se reunindo, mas como um saber histórico com a marca do aprendiz.

Nesse longo caminho, cheio de obstáculos e descontruções, é 
imprescindível uma revisão radical de valores, uma crítica ao modelo pedagógico que esteve e ainda está instituído em nossas escolas e na realidade educacional do Pará.

E muito mais do que essa revisão radical de valores, é ainda necessário restabelecer parâmetros decisórios acerca dos projetos destinados às escolas, vislumbrando-se a elaboração de um projeto educacional coletivo, em parceria com todos os sujeitos envolvidos (alunos(as), professores(as), comunidade rurais e técnicos).

Estamos nos referindo a um projeto de educação rural que não seja apenas um programa a ser implementado nas zonas rurais, mas que, fundamentalmente, desponta em suas próprias estruturas devido às necessidades e perspectivas das populações rurais. (PETTY et al, 1981, p.34).

Fazer uma escola do campo possível, uma escola que leve em conta as peculiaridades e carências dos (as) aluno(as) e a elas se adapte nas metodologias, nos conteúdos e na organização do processo pedagógico (ARROYO, 1991, p.27), e que, ao mesmo tempo, reconheça e valorize o significado social das manifestações culturais e atenda aos interesses coletivos daqueles que dela possam e querem se beneficiar é tarefa dos movimentos sociais atrelados à luta campesina.

Só assim será possível escrever uma outra história da educação, uma história que ainda está por ser feita. Enfim, a proposição que defendemos é que só podemos fazer uma educação verdadeiramente emancipadora, em uma perspectiva (r)evolucionária, apenas se sonharmos (com paixão e utopia) na construção de uma escola rural, fruto da identidade cultural dos grupos sociais que estão no campo, na qual a riqueza cultural esteja aliada à riqueza tecnológica, possibilitando, desta maneira, a formulação de um saber-cultura que permita a realização pessoal e humana dos sujeitos do campo. 


\section{REFERÊNCIAS BIBLIOGRÁFICAS}

ARROYO, Miguel (Org). Da escola carente à escola possível. São Paulo: Edições Loyola 1991.

ASSMANN, Hugo. Reencantar a educação: Rumo à uma sociedade aprendente. 4⿳亠丷a edição. Petrópolis (RJ): Vozes, 2000.

BENJAMIM, Cezar e CALDART, Roseli Salete. Projeto Popular e Escolas do Campo. 2 $2^{\mathrm{a}}$ edição. Brasília: DF: Articulação Nacional por uma educação no Campo, 2001. (Coleção Por um a Educação Básica no Campo № 3).

CALAZANS, Maria Julieta C, et al. Políticas educacionais: Questões e contradições da Educação Rural no Brasil In: WERTEIN, Jorge e BORDENAVE, Juan Diaz (orgs). Educação rural no terceiro mundo: Experiências e novas alternativas. Rio de janeiro: Paz e terra, 1981. p. 161 a 197.

. Para compreender a Educação do Estado no meio rural - Traços de uma trajetória In: THERRIEN, Jacques e DAMASCENO, Maria Nobre (Coords.). Educação e escola no campo. Campinas: Papirus, 1993. p.15 a 40

CALDART, Roseli Salete. A escola do campo em e movimento In: BENJAMIM, Cezar e CALDART, Roseli Salete. Projeto Popular e Escolas do Campo. 2a edição. Brasília: DF: Articulação Nacional por uma educação no Campo, 2001. (Coleção Por um a Educação Básica no Campo no 3).

Educação e movimento: Formação de educadoras e educadores no MST. Petrópolis.Rio de Janeiro: Vozes, 1997.

GIROUX, Henry e SIMON, Roger. Cultura popular e pedagogia crítica: a vida cotidiana com base para o conhecimento curricular In: MOREIRA, Antonio Flávio e SILVA, Tomaz Tadeu da (Orgs). Currículo, cultura e sociedade. $2^{\mathrm{a}}$ edição. São Paulo: Cortez, 1995. p 93 a 124

GIROUX, Henry e MACLAREN, Peter. Formação do professor como uma contraesfera pública: a pedagogia radical como uma forma de política cultural In: MOREIRA, Antonio Flávio e SILVA, Tomaz Tadeu da (Orgs). Currículo, cultura e sociedade. 2ª edição. São Paulo: Cortez, 1995. p 125 a 154 
GOHN, Maria da Glória Marcondes. Movimentos Sociais e Educação. $2^{\underline{a}}$ ed. São Paulo: Cortez, 1994. (Coleção Questões da nossa época; v. 5)

.Educação não-formal e cultura política. 2 2aㅡ. ed. São Paulo: Cortez, 2001. (Coleção Questões da nossa época; v. 71)

NASCIMENTO, Elimar Pinheiro. Educação e desenvolvimento, na contemporaneidade: dilema ou desafio? In: BURSZTYN, Marcel. Ciência, Ética e Sustentabilidade. São Paulo: Cortez, 2001. p.95 a 113

QUEIRÓZ, Maria Isaura Pereira de. Cultura, Sociedade rural, sociedade urbana: Ensaios. Rio de Janeiro: Livros Técnicos e Científicos: São Paulo. Editora da Universidade de São Paulo, 1978.

XAVIER, Libânia Nacif. Para Além do campo educacional: Um estudo sobre o manifesto dos pioneiros da educação nova (1932). Bragança Paulista: EDUSF, 2002.

Fontes documentais:

Programa de educação rural para o estado do Pará: Casas familiares Rurais do Norte e Nordeste, Arcarfar, 1999.

FETAGRI - Regional Sudeste/PA. Projeto Piloto de Ensino Rural. Versão Preliminar, mimeo. s/d.

Projeto Pedagógico da Escola família Agrícola - EFA: Marabá, 2000.

Relatório da Conferência de Educação rural do sul e sudeste do Pará. Mimeo. Marabá-PA/2001.

${ }^{1}$ Doutoranda do Programa de Pós-Graduação em Educação Brasileira da Faculdade de Educação da Universidade Federal do Ceará. Professora do curso de Pedagogia da Universidade Federal do Pará - Campus Universitário de Marabá. E-mail: mrdoma@ufpa.br

2 Optamos por trabalhar com a expressão educação do campo, ao invés de educação rural, por acreditarmos que esta segunda não abarca com a complexidade dos processos educativos que se desencadeiam no interior da realidade educacional do campo. 
3 Segundo Norberto Bobbio "o tema estado pode ser abordado de diferentes pontos de vista" (p.56), utilizamos como conceito de análise de Estado: sociedade jurídica responsável pelo ordenamento social de uma dada sociedade, com poder coativo para agir e legitimar o conjunto de interesses que estiver representando.

${ }^{4}$ Superintendência de Desenvolvimento do Nordeste, Superintendência da Região Sul, Instituto Nacional de Colonização e Reforma Agrária e Superintendência de Desenvolvimento da Amazônia.

5 Desenvolvimento pleno da capacidade intelectual e física, sem perder de vista a reflexão crítica.

6 Para nós a expressão meio rural não dar conta da complexidade do mundo rural e de suas populações por isso no decorrer deste trabalho, em especial em nossas considerações finais, optaremos pela expressão do campo, para designar todos os processos inerentes a essas populações.

${ }^{7}$ A Pedagogia da Alternância permite aos jovens (alunos) alternarem período de vida de estudo e trabalho na escola e com a família na propriedade rural (lote), integrando assim escola, família e comunidade. Portanto, o alvo a ser atingido nesta concepção pedagógica é a formação global/integral da pessoa, levando em considerações as dimensões: intelectual-profissional, humano-social e ético-espiritual. (Projetos pedagógicos da EFA- Marabá, 2002).

8 Em parceria com a Faculdade de Educação - Universidade Federal do Pará vem sendo desenvolvido o curso de Pedagogia da terra a titulo de nível superior.

9 Programa Nacional de Educação na Reforma Agrária (PRONERA) desenvolvido nas áreas rurais.

${ }^{10}$ Relatório do seminário de educação da transamazônica e Xingu-Altamira-PA/1997, Relatório da Conferência de Educação rural do sul e sudeste do Pará-Marabá-PA/2001, Relatório do seminário de "Pesquisa Agroambiental na Região da Transamazônica" - Uruará-PA-1993, Projeto Piloto de Ensino Rural - FETAGRI/SUDESTE/PA, s/d, entre outros.

${ }^{11}$ Homens e mulheres, em uma proposta de co-educação sexual.

Nota dos Editores: Recebido em 19/04/2008. Aprovado em 12/05/2008 